\title{
Binding of C-reactive protein to Aspergillus fumigatus fractions
}

\author{
TINE D. BØRGLUM JENSEN, H. SCHØNHEYDER, P. ANDERSEN and A. STENDERUP
}

\begin{abstract}
Institute of Medical Microbiology, Bartholin Building, University of Aarhus, Department of Medicine, Marselisborg Hospital, DK-8000 Aarhus C, Denmark
\end{abstract}

\begin{abstract}
Summary. Calcium-dependent binding of C-reactive protein (CRP) to Aspergillus fumigatus was determined by enzyme-linked immunosorbent assay. A homogenate of young hyphae was fractionated by hydrophobic interaction chromatography followed by gel filtration. High CRP-binding activity was found in a fraction of mol. wt $c$. 500,000 which was characterised by strong binding to the hydrophobic column. Three fractions of less conspicuous CRP-binding activity were identified (c. 500000,150000 and 150000-50000 mol. wt respectively). In these four fractions, phosphorylcholine was detected by an anti-phosphorylcholine mouse hybridoma antibody. Some CRPbinding activity in fractions with low affinity for the hydrophobic column did not correspond closely with the presence of phosphorylcholine. It is suggested that Creactive substance in $A$. fumigatus is heterogeneous. The C-reactive substances did not correspond with fractions containing major antigens (470 000 and $250000 \mathrm{~mol}$. wt respectively) which elicit a strong immune response in man.
\end{abstract}

\section{Introduction}

Components of various micro-organisms including bacteria, fungi and parasites, capable of interacting with $\mathrm{C}$-reactive protein (CRP), are referred to as C-reactive substances (Pepys and Longbottom, 1971; Gotschlich et al., 1982). CRP belongs to a group of serum proteins, known as acute-phase reactants, which circulate in increased amounts during infection, inflammation and tissue damage. CRP complexed with calcium has high affinity for polyanions, galactose residues and phosphorylcholine which have been found in some $\mathrm{C}$-reactive substances (Gotschlich and Edelman, 1967; Volanakis and Kaplan, 1971; Gotschlich et al., 1982). A calcium-independent binding to polycations has also been described (DiCamelli et al., 1980).

Aspergillus fumigatus contains C-reactive substance. Longbottom and Pepys (1964) described a precipitin reaction involving aspergillus $\mathrm{C}$-reactive substance and CRP and pointed to this as a source of error in the serodiagnosis of aspergillosis. Pulmonary aspergillosis occurs in different clinical forms (Pennington, 1980); complement activation may be important in some of them. This activation may be elicited by antigen-antibody complexes but other mechanisms could play a role. The interaction of CRP and C-reactive substances may activate the classical complement pathway (Kaplan and Vola-

Received 4 Mar. 1985; revised version accepted 21 Jun. 1985. nakis, 1974) and thus aspergillus C-reactive substance may participate in the pathogenesis of aspergillus-related diseases through complement activation. In this study we have investigated some of the characteristics of $A$. fumigatus $C$-reactive substance.

\section{Materials and methods}

\section{Preparation of $C R P$}

CRP was prepared from ascitic fluid from patients with either ovarian or mammary carcinoma, admitted to the Department of Oncology, Radiumstationen, Municipal Hospital, Aarhus. Specimens were tested for CRP by double immunodiffusion (ID) against rabbit anti-human CRP (Dakopatts, Denmark). Only samples with titres above two were used, and CRP was prepared from such samples by anion exchange chromatography essentially as described by Johnson and Prellner (1977). The fractions obtained by chromatography were tested for CRP by ID. Quantitation of purified CRP was done by radial immunodiffusion (RI) in barbital-buffered agarose (HSA, Litex, Denmark), $p \mathrm{H} 8.2$, with $1.5 \mu$ l of anti-CRP (Dakopatts) added $/ \mathrm{cm}^{2}$. The purity of CRP was assessed by crossed immuno-electrophoresis (CIE) in agarose (LSL, Litex) against a homologous antiserum with a Tris-

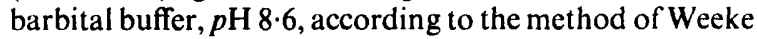
(1973) with $\mathrm{Na}_{2}$ EDTA $10 \mathrm{mmol} / \mathrm{L}$ added. Plates measured $7 \times 7 \mathrm{~cm}$ and $10 \mu 1$ of antiserum were added per $/ \mathrm{cm}^{2}$. The homologous antiserum was raised in three New Zealand white rabbits by immunisation with $75 \mathrm{mg}$ of 
purified CRP every second week for at least 2 months. CIE against the homologous antiserum revealed two faint contaminants together with a CRP arc which crossreacted with a known CRP antiserum (Dakopatts) by intermediate gel technique. The contaminants did not react with anti-IgG, -IgA or -IgM (Dakopatts) added to the intermediate gel.

The protein content of purified CRP was assayed by the Bio-Rad method (Bio-Rad, USA) with human serum albumin as the reference (KabiVitrum, Sweden).

\section{A. fumigatus fractionation}

A. fumigatus NCPF 2109 was grown in Czapek-Dox broth at $37^{\circ} \mathrm{C}$ for $2-4$ days, harvested and ruptured with a freeze-press technique (Eaton, 1962). The supernate referred to as ruptured mycelium, obtained by centrifugation at $35000 \mathrm{~g}$ for $45 \mathrm{~min}$ at $4 \mathrm{C}$, was submitted to hydrophobic interaction chromatography and gel filtration as previously described (Schønheyder and Andersen, 1984a). In brief, $40 \mathrm{ml}$ of ruptured mycelium with $\mathrm{NaCl}$ added to a concentration of $4 \mathrm{M}$ were loaded on a Phenyl-Sepharose CL-4B column equilibrated in Tris

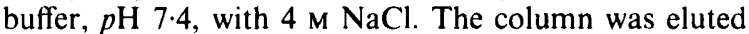
successively with Tris buffers of decreasing $\mathrm{NaCl}$ molarity $(4 \mathrm{M}, 2 \mathrm{M}, 0.15 \mathrm{M})$ and with twice-distilled water. At each elution step, fractions of peak absorbance at $280 \mathrm{~nm}$ (referred to by their $\mathrm{NaCl}$ molarity) were pooled, concentrated by pressure dialysis in collodion bags (Sartorius, FRG) and loaded on a Sephadex G-200 column (Pharmacia Fine Chemicals). The effluent of this column was collected in fractions of $4 \mathrm{ml}$ and assessed for CRP. binding activity. An antigen complex of mol. wt 470000 and a catalase antigen were identified by rocket immunoelectrophoresis with rabbit antisera against these fractions. Immunoprecipitated catalase was visualised by adding hydrogen peroxide to the dried gel (Schønheyder and Andersen, 1984b).

\section{CRP-binding assay}

An enzyme-linked immunosorbent assay (ELISA) was developed for detection of CRP binding to aspergillus fractions. All determinations were done in duplicate, and in all experiments two identical sets of ELISA microtitration plates (Immunoplate I, Nunc, Denmark) were processed, i.e., one set saturated with calcium for optimal CPR binding, and one exposed to $\mathrm{Na}_{2}$ EDTA for dissociation of calcium-dependent CRP binding.

Undiluted Sephadex G-200 fractions (100 $\mu$ l) and serial ten-fold dilutions of these fractions in $0.5 \mathrm{M}$ carbonate buffer, $p \mathrm{H} 9.6$ (Voller $e t$ al., 1976), were added to the wells and left for $1 \mathrm{~h}$ at $37^{\circ} \mathrm{C}$. After a wash in TBS-Tw buffer (0.05 M Tris, $0.15 \mathrm{M} \mathrm{NaCl}, 10 \mathrm{~mm} \mathrm{CaCl}_{2}$, Tween $200.05 \%$ $\mathrm{v} / \mathrm{v}, p \mathrm{H} \mathrm{7.4)} 50 \mu \mathrm{l}$ of CRP (3.5g/ml of TBS-Tw) was added to each well and plates were left overnight at $4^{\circ} \mathrm{C}$. This concentration of CRP was determined as optimal by using serial dilutions of CRP against one $A$. fumigatus CRP-binding fraction. After a wash in TBS-Tw, $50 \mu$ l of peroxidase-labelled rabbit anti-human CRP (Dakopatts) diluted 1 in 300 in TBS-Tw were added to each well and left for $2 \mathrm{~h}$ at $37^{\circ} \mathrm{C}$. One set of ELISA plates was then rinsed in TBS-Tw and $50 \mu \mathrm{l}$ of substrate- $O$-phenylenediamine dihydrochloride (OPD) -in citrate-phosphate buffer, $p \mathrm{H} 5 \cdot 6$, were added to each well and incubated for $5 \mathrm{~min}$ at room temperature. The reaction was stopped by adding $100 \mu \mathrm{l} 1 \mathrm{M} \mathrm{H}_{2} \mathrm{SO}_{4}$ to each well.

The replica set of plates was washed in a $\mathrm{Na}_{2}$ EDTA containing buffer $(0.05 \mathrm{M}$ Tris, $0.15 \mathrm{M} \mathrm{NaCl}, 20 \mathrm{~mm}$ $\mathrm{Na}_{2}$ EDTA, Tween $200.05 \% \mathrm{v} / \mathrm{v}, p \mathrm{H} \mathrm{7.4)}$ and then the OPD substrate was added and allowed to react as described above. The absorbance of wells was read at 490 $\mathrm{nm}$ in absorbance units with a filter photometer (MR 590, Dynatech, USA). The calcium-dependent CRP binding was determined as the difference of means of absorbance of wells with calcium and wells washed with $\mathrm{Na}_{2}$ EDTAcontaining buffer.

\section{Anti-phosphorylcholine assay}

A monoclonal antibody against phosphorylcholine from a mouse hybridoma was kindly provided by $\mathrm{Dr} U$. Skov Sørensen, Statens Seruminstitut, Copenhagen (Sørensen et al., 1984). This was used for demonstration of phosphorylcholine ligands in aspergillus fractions as follows. Wells coated with $A$. fumigatus fractions as described above were incubated overnight at $4^{\circ} \mathrm{C}$ with 50 $\mu l$ of mouse anti-phosphorylcholine antibody diluted 1 in

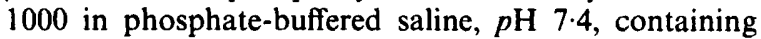
Tween $200.05 \% \mathrm{v} / \mathrm{v}$ (PBS-Tw). After a rinse in PBS-Tw, $50 \mu \mathrm{l}$ of peroxidase-labelled rabbit anti-mouse immunoglobulin (Dakopatts) diluted 1 in 400 in PBS-Tw were added and left for $2 \mathrm{~h}$ at $37^{\circ} \mathrm{C}$. After a rinse in PBS- $\mathrm{Tw}$, OPD substrate was added and the enzymatic reaction was allowed to proceed for $5 \mathrm{~min}$. All determinations were done in duplicate and wells with PBS-Tw added instead of anti-phosphorylcholine served as blanks. The phosphorylcholine activity was measured by the difference of means of absorbance at $490 \mathrm{~nm}$ with anti-phosphorylcholine added and with PBS-Tw added instead of mouse antibody.

\section{Results}

\section{CRP binding assay}

The CRP-binding activities of the A. fumigatus fractions were determined with and without calcium and the differences were taken to indicate the calcium-dependent binding activities. Investigation of four separate batches of $A$. fumigatus ruptured mycelium exhibited the same pattern of calciumdependent CRP-binding activity. Results from one representative experiment are shown in the figure. Calcium-dependent CRP-binding activity was detected in all four eluates $(4 \mathrm{M}, 2 \mathrm{M}, 0.15 \mathrm{M}$ and $\mathrm{H}_{2} \mathrm{O}$ ) obtained by hydrophobic interaction chromatography, the highest activity being asso- 
ciated with the $\mathrm{H}_{2} \mathrm{O}$ eluate. The absorbance of all fractions in the absence of calcium was below 0.5 , which indicated little calcium-independent CRPbinding activity of $A$. fumigatus fractions.

By gel filtration of the $\mathrm{H}_{2} \mathrm{O}$ eluate, the most prominent calcium-dependent CRP binding activity was found in fractions with a mol. wt of $c$.
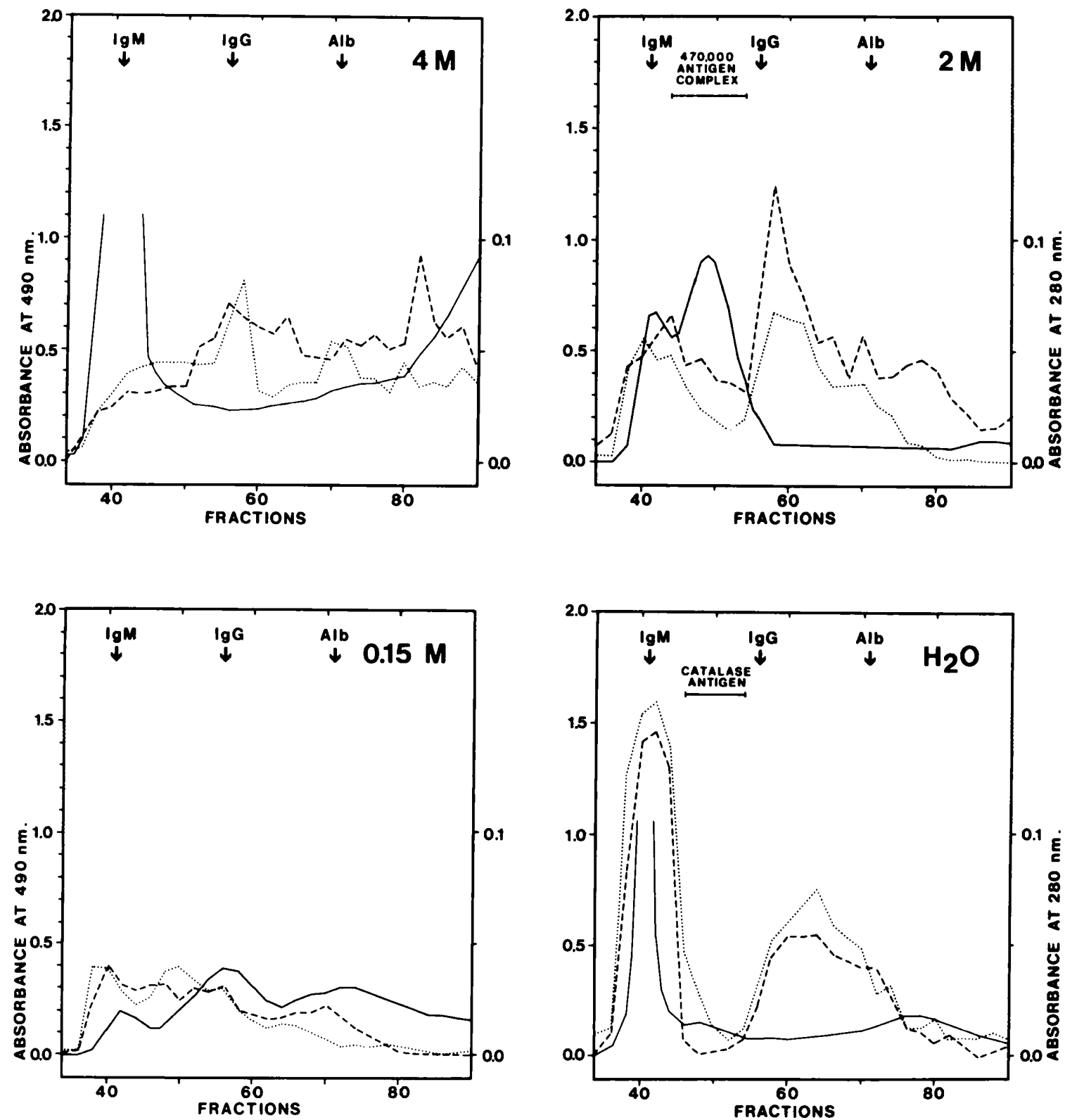

Fig. Calcium-dependent CRP binding (. . . .) and anti-phosphorylcholine reactivity (- . - - in $A$. fumigatus fractions as measured by ELISA $\left(\mathrm{A}_{490 \mathrm{~nm}}\right)$. The first chromatographic step was hydrophobic interaction chromatography producing four eluates $(4 \mathrm{M}, 2$ M, $0.15 \mathrm{M}$ and $\mathrm{H}_{2} \mathrm{O}$ ) of increasing hydrophobicity. Eluates were subsequently processed on a Sephadex G-200 column and effluents were collected in fractions of $4 \mathrm{ml}$. The $A_{280 \mathrm{~mm}}$ profile (——) and mol.-wt markers-IgM, IgG and human serum albumin (Alb)-are indicated. 
vity. The $2 \mathrm{M}$ eluate exhibited two distinct peaks of CRP-binding activity, one with a mol. wt of 500000 and one of $c .150000$. Only the highest mol. wt peak was associated with high $A_{280}$ activity. A 470000 mol. wt antigen complex (Schønheyder and Andersen, $1984 b$ ) eluted in a prominent $A_{280}$ peak and was not associated with conspicuous CRP-binding activity. In the $4 \mathrm{M}$ eluate all fractions showed some CRP-binding activity whereas the $0.15 \mathrm{~m}$ eluate had little activity.

\section{Anti-phosphorylcholine assay}

A monoclonal antibody against phosphorylcholine was used for demonstration of phosphorylcholine ligands in A. fumigatus fractions. The antiphosphorylcholine assay for all eluates showed an activity profile very similar to that of the calciumdependent CRP binding (figure). It should especially be noticed that CRP-binding maxima in $\mathrm{H}_{2} \mathrm{O}$ and $2 \mathrm{M}$ eluates coincided with high phosphorylcholine activity. However, some discrepancies were observed. In the $2 \mathrm{M}$ and $4 \mathrm{M}$ eluates the phosphorylcholine ligand was detectable by anti-phosphorylcholine beyond fraction 75 , where no or little CRP binding was seen.

\section{Discussion}

Combined hydrophobic interaction chromatography and gel filtration has previously been found to resolve several distinct $A$. fumigatus antigens (Schønheyder and Andersen, 1984a and $b$ ) and the present study demonstrates that a number of these fractions exhibit calcium-dependent CRP-binding activity. The fraction with the highest binding capacity had a mol. wt of $c .500000$. Phosphorylcholine has been demonstrated to be the determinant group in many microbial C-reactive substances (Volanakis and Kaplan, 1971; Baldo et al., 1977; Gotschlich et al., 1982). The anti-phosphorylcholine reactivity profile corresponded with the
CRP-binding activity, indicating that some Creactive substances from $A$. fumigatus contain phosphorylcholine. It should also be mentioned, however, that phosphorylcholine was detected in some fractions without conspicuous CRP binding.

In the $4 \mathrm{M}$ eluate, fractions with a broad range of mol. wt had CRP-binding activity and this activity did not correspond closely with the presence of phosphorylcholine. Thus it is possible that in these fractions CRP was binding to other ligands, i.e., galactose residues or complexes containing nucleic acids (Robey et al., 1984). The results suggest that $A$. fumigatus $\mathrm{C}$-reactive substance is not a single substance but is composed of different molecules with a broad range of mol. wt and some sharing the phosphorylcholine group.

It should be noticed that the CRP-binding fractions were different from fractions previously found to exhibit the highest antigenic activity in man. Antibodies to the $470000-\mathrm{mol}$. wt fraction occur in the majority of healthy subjects and in patients with aspergillus-related disorders. This antigen complex contains protein and carbohydrate (Schønheyder and Andersen, 1984b), but it was found neither to bind CRP nor to contain phosphorylcholine and it seems therefore to be unrelated to $\mathrm{C}$-reactive substance. A catalase-containing fraction of the $\mathrm{H}_{2} \mathrm{O}$ eluate also induces a strong immune response in patients with aspergillosis (Schønheyder and Andersen, 1984b) and this fraction likewise appeared to be unrelated to aspergillus C-reactive substance.

The high-mol.-wt fraction of the $\mathrm{H}_{2} \mathrm{O}$ eluate identified as the major CRP-binding fraction may be of particular interest for CRP-mediated reactions towards $A$. fumigatus.

This work was supported by grants from Kong Christian den Tiendes Fond, Nationalforeningen til Bekæmpelse af Tuberkulose og Sygdomme i Aandedrætsorganerne, and P. Carl Petersens Fond. We are indebted to Dr Signe Stenholt, Radiumstationen, Municipal Hospital, Aarhus, for supplying ascitic fluid and to Dr U. Skov Sørensen, Statens Seruminstitut, Copenhagen, for donating the anti-phosphorylcholine antibody.

\section{REFERENCES}

Baldo B A, Fletcher T C, Pepys J 1977 Isolation of a peptidopolysaccharide from the dermatophyte Epidermophyton floccosum and a study of its reaction with human C-reactive protein and a mouse anti-phosphorylcholine myeloma serum. Immunology 32:831-842.

DiCamelli R, Potempa L A, Siegel J, Suyehira L, Petras K, Gewurz H 1980 Binding reactivity of C-reactive protein for polycations. Journal of Immunology 125:1933-1938.

Eaton N R 1962 New Press for disruption of microorganisms. Journal of Bacteriology 83: 1359-1360.
Gotschlich E C, Edelman G M 1967 Binding properties and specificity of $\mathrm{C}$-reactive protein. Proceedings of the National Academy of Sciences of the USA 57:706-712.

Gotschlich E C, Liu T Y, Oliveira E 1982 Binding of C-reactive protein to $\mathrm{C}$-carbohydrate and $\mathrm{PC}$-substituted protein. Annals of the New York Academy of Science 389:163-171.

Johnson U, Prellner K 1977 Purification of C-reactive protein on DEAE-cellulose by a simple twostep procedure utilizing the calcium-dependency of the protein. Biochimica et Biophysica Acta 495:349-353.

Kaplan M H, Volanakis J E 1974 Interaction of C-reactive protein complexes with the complement system. I. Con- 
sumption of human complement associated with the reaction of C-reactive protein with pneumococcal C-polysaccharide and with the choline phosphatides, lecithin and sphingomyelin. Journal of Immunology 112:2135-2147.

Longbottom J L, Pepys J 1964 Pulmonary aspergillosis: Diagnostic and immunological significance of antigens and $C$ substance in Aspergillus fumigatus. Journal of Pathology and Bacteriology 88: 141-151.

Pennington J E 1980 Aspergillus lung disease. Medical Clinics of North America. 64:475-490.

Pepys J, Longbottom J L 1971 Antigenic and C-substance activities of related glycopeptides from fungal, parasitic and vegetable sources. International Archives of Allergy and Applied Immunology 41:219-221.

Robey F A, Jones K D, Tanaka T, Liu T Y 1984 Binding of Creactive protein to chromatin and nucleosome core particles. A possible physiological role of C-reactive protein. Journal of Biological Chemistry 259:7311-7316.

Schønheyder H, Andersen P 1984a Fractionation of Aspergillus fumigatus antigens by hydrophobic interaction chromato- graphy and gel filtration. International Archives of Allergy and Applied Immunology 73:231-236.

Schønheyder H, Andersen P $1984 b$ IgG antibodies to purified Aspergillus fumigatus antigens determined by enzymelinked immunosorbent assay. International Archices of Allergy and Applied Immunology 74:262-269.

Sørensen U B S, Agger R, Bennedsen J, Henrichsen J 1984 Phosphorylcholine determinants in six pneumococcal capsular polysaccharides detected by monoclonal antibody. Infection and Immunity 43:876-878.

Volanakis J E, Kaplan M H 1971 Specificity of C-reactive protein for choline phosphate residues of pneumococcal Cpolysaccharide. Proceedings of the Society for Experimental Biology and Medicine 136:612-614.

Voller A, Bidwell D E, Bartlett A 1976 Enyzme immunoassays in diagnostic medicine. Theory and practice. Bulletin of the World Health Organization 53:55-65.

Weeke B 1973 Crossed immunoelectrophoresis. Scandinavian Journal of Immunology Suppl. 1, 47-56. 